\title{
Perlawanan Strategis Perempuan terhadap Eksploitasi Laki-laki dalam Novel Claudine en Menage (1902) Karya Gabriele Sidonie Colette
}

\section{(Women's Strategic Resistance to Male Exploitation in Gabriele Sidonie Colette's Novel Claudine en Menage (1902))}

\author{
Yuniarti Sibuea \\ Wening Udasmoro \\ Hayatul Cholsy \\ Program Studi Sastra Prancis, Universitas Gadjah Mada \\ Jalan Sosio Humaniora, Bulaksumur, Yogyakarta \\ Tel.: +62(274)513096 \\ Surel: artisibuea@yahoo.co.id
}

Diterima: 9 September 2020

Direvisi: 25 Oktober 2020

Disetujui: 2 November 2020

\begin{abstract}
Abstrak
Penelitian ini bertujuan untuk mengeksplorasi ideologi novel Claudine en Menage (1902) terkait dengan perlawanan strategis perempuan terhadap eksploitasi laki-laki dan mengajak pembaca untuk membuka paradigma baru yang lebih luas mengenai perlawanan perempuan tersebut. Claudine en Menage adalah novel karya seorang pengarang Prancis, Colette. Novel ini menceritakan tentang seorang perempuan yang hidup sebagai istri yang mengalami eksploitasi berlapis karena ras, budaya, dan seksualitasnya yang dilakukan oleh orang-orang terdekatnya, yaitu ayah dan suaminya. Penelitian ini menggunakan teori perlawanan perempuan dari Hélène Cixous, yang berpendapat bahwa perempuan dengan keahlian dan kemampuannya menulis mampu keluar dari belenggu penindasan yang mereka alami. Teori interseksionalitas dari Kimberlé Crénshaw, yang menerangkan tentang diskriminasi ganda perempuan yang bersifat interseksional yang memuat aspek ras, budaya, agama, serta seksualitas juga dijadikan lensa pendukung di dalam tulisan ini. Penelitian ini menggunakan metode analisis isi cerita dengan melakukan, pertama pengumpulan data terkait dengan aspek-aspek perlawanan perempuan di dalam novel, kedua melakukan klasifikasi pola-pola yang ditemukan pada data yang telah diseleksi tersebut, dan ketiga melakukan analisis data pada kemampuan perempuan keluar dari belenggu patriarki dan mampu menjadi perempuan independen dengan kemampuan yang mereka miliki.
\end{abstract}

Kata kunci: eksploitasi, interseksionalitas, perempuan, perlawanan perempuan

\begin{abstract}
This study aims to reveal women's resistance to male exploitation depicted in a novel entitled Claudine en Menage written by a French author, Colette in 1902. Claudine en Menage narrates a woman's experiences with racial, cultural, and sexual exploitation at the hands of her father and husband. To pursue the aim of this study, qualitative method was used together with content analysis approach. To analyse the data, Hélène Cixous' theory of struggle and Kimberlé Crénshaw's theory of intersectionality were also used. The results of this study showed that
\end{abstract}


Claudine, the main female character, had the right to fulfil her sexual desire and opportunity to have a voice. Claudine was also depicted as a woman who was capable of being an independent woman, holding on to her abilities, and not depending on living on other people, especially her husband. Her courage and strong self-confidence portrayed in the novel made her take steps to separate from her husband and leave her dark past which was full of compulsion. Thus, it can be concluded that the courage of Claudine's character portrayed in the novel was not an ordinary resistance in the 19th century, when the position of women was still in the world of patriarchy and women were taboo for activities outside the domestic space.

Keywords: exploitation, intersectionality, women, women's resistance

\section{PENDAHULUAN}

Persoalan mengenai perempuan yang terdominasi secara struktural telah menjadi debat yang cukup panjang sejak Second Wave of Feminisme pada tahun 1970-an sampai sekarang. Ide dasarnya adalah bahwa ada ketimpangan representasi perempuan dalam wilayah-wilayah yang bervariasi, baik secara sosial, politik, maupun kultural (Mottier 2013). Pandangan terkait perempuan sebagai sosok yang lemah dan tidak berpotensi di ranah publik membuat ruang gerak perempuan terbatas. Hak-hak perempuan diambil dan diatur oleh pihak yang berkuasa. Kuatnya budaya patriarki yang diturunkan dari generasi ke generasi membuat aturan tersebut kuat dan sulit dihilangkan (Sentana 2016, 121). Pada abad ke-19, misalnya, terbatasnya ruang gerak perempuan terutama dalam hal pendidikan membuat mereka kurang mendapatkan wawasan di luar ranah domestik (Udasmoro 2015b). Perempuan secara kultural diposisikan sebagai agen reproduktif yang tugasnya adalah untuk mengelola ranah domestik. Hal ini menyebabkan perempuan dipasung oleh aturan-aturan yang mengikatnya. Pembagian ranah publik dan privat sebetulnya adalah pembagian kerja yang bersifat kultural dan sosial (Nasiru 2017, 27). Artinya, pembagian kerja itu sebetulnya bisa bersifat komplementer atau saling menggantikan. Namun dalam praktiknya, pembagian ranah publik dan domestik tersebut selalu dikaitkan dengan fungsi biologis perempuan dan laki-laki. Sebagai konsekuensinya, karena perempuan secara biologis diasumsikan akan mengandung dan melahirkan anak, maka selurut tatanan yang berkaitan dengan anak diserahkan kepada perempuan (Lee Bartky 1998). Salah satu sifat yang dianggap melekat pada perempuan adalah sifat penurut, yang berarti menuruti segala aturan yang diberikan rejim laki-laki kepadanya. Aturan-aturan tersebut dibuat oleh rejim dominan, yang dalam hal ini didominasi oleh kultur dan sistem laki-laki, yang disebut dengan budaya patriarki (Yuval-Davis 2011).

Terbatasnya pengetahuan perempuan berimplikasi pada pemahaman yang tidak bersifat setara dalam masyarakat. Sebagai contoh, perempuan yang tidak menikah serta, tidak dapat bereproduksi bukanlah perempuan yang diharapkan. Prestasi perempuan hanya dilihat dari fungsi reproduksinya dan bukan dari kemampuan intelektualnya. Pandangan budaya patriarki tentang eksistensi perempuan hanya terlihat ketika perempuan berhasil di ranah domestik (Udasmoro 2012). Sebagai konsekuensi sosialnya, perempuan merasa harus memenuhi keinginan fungsi reproduktif tersebut dengan cara berbondong-bondong untuk menikah muda, menjadi orang tua muda, serta tanpa memikirkan kesiapan atas dirinya (MacClintock 1993). Banyak pengalaman perempuan yang menunjukkan bahwa mereka terpaksa menikah dengan seseorang yang tidak mereka cintai atau yang mereka yakin akan membahagiakan mereka. Yang terpenting adalah bahwa ekspektasi sosial tersebut mereka penuhi.

Sistem patriarki ini menjadikan perempuan sering kali mengalami eksploitasi dari individu yang berkuasa atas dirinya. Eksploitasi dari sistem patriarki ini seringkali berlapis sifatnya. Sebagai contoh, ketika seorang perempuan belum menikah, maka eksploitasi datang dari ayahnya. Sementara itu, ketika dia sudah menikah maka eksploitasi datang dari suaminya (Zabihzadeh, Hashim, \& Wei 2015). Satu cara untuk menentang kuatnya budaya ini adalah melalui keberanian untuk memutus tali rantai 
tindasan eksploitasi atas perempuan. Banyak perempuan yang mengalami belenggu ketindasan ini juga memikirkan bagaimana cara mereka untuk keluar tanpa menyakiti pihak-pihak di sekelilingnya.

Claudine en Menage menceritakan pengalaman perempuan bernama Claudine yang hidup di bawah tekanan dan eksploitasi laki-laki, yakni dari ayah dan terutama dari suaminya. Eksploitasi yang dilakukan suaminya terutama terkait dengan persoalan ekonomi dan juga pekerjaan tanpa dibayar. Suami Claudine menyuruhnya menulis buku, semacam novel dan karya fiksi lain untuk tujuan ekonomi, tetapi diakui sebagai tulisan suaminya. Suaminya menjadi terkenal karena karya Claudine sekaligus mendapatkan Kapital finansial karena terjualnya buku-buku tersebut. Selain itu, suaminya yang seorang bangsawan beserta lingkungannya melakukan penghinaan terhadap Claudine yang secara sosial berasal dari kelas sosial berbeda. Claudine juga berasal dari desa sehingga suaminya yang merasa lebih tinggi derajat sosialnya sering melakukan perselingkuhan dengan perempuan lain. Hal ini memunculkan trauma dalam diri Claudine. Namun, alih-alih melakukan perlawanan berbentuk penentangan atau perlawanan frontal, Claudine memilih untuk mengalihkan situasi ketidaksenangannya dengan menjalin hubungan dengan seorang perempuan. Pelarian diri ini diceritakan di dalam novel sebagai bagian dari perlawanan perempuan terhadap sistem patriarki yang diposisikan mendominasi dan memosisikan perempuan dalam posisi tidak setara dengan laki-laki. Untuk itu, penelitian ini bertujuan untuk melihat perlawanan perempuan lewat transformasi hasrat seksual dari hasrat kepada laki-laki ke hasrat kepada perempuan. Pertanyaan yang diajukan, pertama, bagaimana praktik eksploitasi yang dialami perempuan di dalam Claudine en Menage? Kedua, bagaimana transformasi hasrat seksual sebagai bagaian dari perlawanan simbolik dilakukan oleh perempuan?

\section{METODE}

Dalam meneliti perlawanan perempuan dalam novel Claudine en Menage ini, langkah pertama yang dilakukan adalah pengumpulan data. Data primer dilakukan dengan cara melakukan pembacaan mendalam dan secara berulang terhadap novel Claudine En Menage (1902). Korpus data didapatkan dari pencatatan terhadap bagian-bagian kalimat dan paragraf yang berhubungan dengan perlawanan perempuan. Data-data tersebut diklasifikasi sesuai dengan pola-pola perlawanan yang ditemukan di dalam isi cerita. Data yang telah diklasifikasi dan ditemukan pola-pola perlawanannya dihubungkan dengan teori-teori yang digunakan untuk mendapatkan pemahaman yang komprehensif.

\section{HASIL DAN PEMBAHASAN}

\section{Latar Belakang Perlawanan Perempuan: Pandangan Perkawinan sebagai Alat Penindasan}

Keberagaman ras dan kedudukan yang dimiliki setiap orang membuktikan adanya perbedaan dalam tingkah laku atau kebiasaan setiap individu (Lon dan Widyawati 2018, 273). Sebagai contoh, seseorang dengan status sosial rendah yang terbiasa dengan lingkungan, dan orang-orang di sekitarnya, membuat mereka terbiasa dengan keadaannya tanpa rasa sungkan dengan orang lain. Hal ini berbeda saat seseorang yang mencoba masuk ke lingkungan baru, yang akan mengalami cultural shock terkait halhal baru di sekitarnya. Perbedaan yang dimiliki seseorang dengan perbedaan latar belakang kelas sosial, membuat setiap individu tersebut harus mampu menyesuaikan kebiasaan baru dengan sekelompok orang di sekelilingnya, dan biasa terjadi saat pernikahan (Lon dan Widyawati 2018, 275).

Diskriminasi kerap dialami oleh perempuan dari berbagai arah, baik dari segi profesi, kedudukan, serta seksualitasnya. Sebagai contoh menurut Crénshaw, kebanyakan perempuan berkulit hitam menjadi sasaran diskriminasi perihal ras dan pekerjaan di tengah masyarakat (Crenshaw 1989). Kajian dengan penelitian ini secara khusus digunakan untuk mengupas dan memperdalam diskriminasi terhadap perempuan yang besifat multidimensional, yakni terkait dengan persoalan gender, ras, etnisitas, usia dan sebagainya (Mohanty 2003). Menurut Crénshaw, posisi ketertindasan perempuan kulit hitam diibaratkan dengan perjalanan di perempatan yang memungkinkannya datang dan pergi dari empat 
penjuru, di antaranya ras, gender, agama, dan orientasi seksual (Crenshaw 1989). Apabila terjadi kecelakaan di perempatan tersebut, akan berakibat pada kendaraan dari berbagai arah. Istilah tersebut berkaitan dengan persoalan perempuan di perempatan, ketika perempuan mengalami kecelakaan maka akan mengalami luka yang disebabkan oleh diskriminasi seks dan ras yang datang dari empat penjuru. Penggambaran Crenshaw ini terefleksi di dalam karya Colette tersebut. Klasifikasi sosial antara orang kota dengan orang desa serta golongan atas dan bawah dideskripsikan di dalam novel tersebut.

Ah! c'est vrai, je suis la femme de Renaud, ici, comme à Montigny il est le mari de Claudine.

Ces Parisiens parlent bas, mais les oreilles des gens du Fresnois entendraient pousser l'herbe. On dit : «C'est bien jeune. » On dit : «Trop brune... l'air mauvais... - Comment, trop brune? Elle a des boucles châtain. - Ces cheveux courts, c'est pour forcer l'attention! Renaud a du goût pourtant. » On dit : « D'où ça sort-il ? - C'est montmartrois. - C'est slave, le menton petit et les tempes larges. - Ça sort d'un roman unisexuel de Pierre Louÿs... Quel âge a-t-il donc, pour se plaire déjà aux petites filles, Renaud ? "Renaud, Renaud... Voilà qui est caractéristique : on ne le désigne jamais que par son prénom (Colette 1973, 61).

(Ah! Benar, aku istri Renaud, di sini, seperti di Montigny Renaud adalah suami Claudine. Orang-orang Paris ini berbicara dengan pelan, tetapi orang-orang Fresno akan mendengarnya. Katanya : «Ini sangat muda. «Mereka mengatakan : «Terlalu gelap ... terlihat buruk ... - Bagaimana, terlalu coklat? Rambutnya ikal berwarna coklat. - Rambut pendek ini untuk menarik perhatian! Renaud punya selera. Mereka berkata: » Dari mana asalnya?" - dari Montmartrois. - Ini Slavik, dagu kecil dan pelipis lebar. - Itu muncul dari novel unisex karya Pierre Louÿs ... - Berapa usianya, untuk menyenangkan gadis kecil, Renaud? » Renaud, Renaud ... Ini ciri khas: kamu tidak pernah menunjuknya kecuali dengan nama depannya.)

Pernikahan dengan latar belakangan budaya dan kelas sosial yang berbeda, mempertemukan perbedaan yang harus saling menerima dan menghargai. Kebiasaan yang belum ditemui sebelumnya membuat seseorang akan mengalami penyesuaian baik atau pun buruk. Penyesuaian yang dialami Claudine saat menikah, yaitu ia mengalami penyesuain buruk dengan perbedaan kulit yang dimilikinya. Percakapan tersebut menunjukkan bahwa terdapat interseksionalitas struktural yang mengarah dalam persoalan ras terhadap perempuan. Claudine berasal dari kota kecil di Prancis, dan ia adalah seorang gadis desa yang polos dan naif. Setelah ia menjadi istri seorang bangsawan, untuk pertama kali Claudine bertemu dengan kelompok sastrawan bangsawan seperti Renaud. Dari pertemuan tersebut, rekan kerja Renaud menilai bahwa penampilan Claudine sebagai istri seorang Renaud dianggap tidak pantas. Mereka seolah merendahkan Renaud dengan pilihannya terhadap Claudine, terlebih Renaud dikenal sebagai playboy. Renaud yang dicap sebagai playboy dirasa tidak pantas menikahi Claudine, karena tidak segolongan dengan lingkungannya (Humaeni 2016, 178). Hal ini membuat Claudine semakin tidak percaya diri, terkait dirinya yang berasal dari kota kecil dan kemudian bergabung dengan golongan bangsawan.

Bagi kebanyakan orang, salah satu cara menentukan kelas sosial seseorang dilihat dari warna kulit, putih dan hitam. Kulit putih yang berarti cerah dikonstruksikan sebagai sesuatu yang baik dan memiliki kedudukan tinggi atau superior, sedangkan kulit hitam identik dengan kegelapan, kesengsaraan, kemiskinan yang berada di kelas bawah atau inferior (Basuki dan Hayuningsih 2015; Collins 2000). Dari pemikiran rekan kerja Renaud menegaskan bahwa Claudine adalah perempuan yang berbeda dan perbedaan itu membuktikan tingkat sosial yang dimiliki Claudine.

Kebersaaman antara Claudine dan Renaud di sebuah restaurant terganggu akibat pandangan Renaud terhadap perempuan lain. Renaud terpesona melihat paras perempuan lain yang lebih menawan sehingga mereka saling bersaut sapa. Namun, hal ini menggoyahkan perasaan Claudine karena 
Claudine tidak mengharapkan suaminya menebar pesona kepada perempuan selain dirinya. Hal ini membuat Claudine merasa bahwa dirinya mulai tidak dihargai oleh suaminya. Tekanan begitu berat dihadapkan kepada Claudine sehingga ia tidak memiliki ruang dengan seseorang yang dipercayainya. Adanya perbandingan dalam paras perempuan membuat Renaud tergoda untuk menggoda perempuan lain. Renaud sebagai seorang laki-laki merasa bahwa dirinya mampu untuk memiliki segalanya melalui kepopularitasannya sebagai penulis dan keturunan bangsawan, sehingga apabila ia kehilangan Claudine, ia tetap dengan mudah mendapatkan perempuan.

"Pomme, poursuit Renaud qui mousse de plaisir, je vous donne ce sac-là si vous m'embrassez... Tu permets, Claudine?" (Colette 1973, 36).

("Pomme (sahut Renaud penuh gairah) saya memberi Anda tas ini jika Anda menciumku ... Apakah kamu keberatan, Claudine?")

Cap playboy dalam diri Renaud tidak tertahan saat ia melihat perempuan muda. Dalam percakapan di atas menjelaskan bahwa Renaud ingin memenuhi hasrat seksualnya melalui ciuman dari Pomme, seorang gadis muda yang tinggal di sekolah asrama lama Claudine. Melalui pemberian tas kepada Pomme, Renaud ingin mendapatkan ciuman sebagai imbalan atas pemberiannya. Namun, sebelum Renaud mendapat ciuman tersebut, tidak ragu bagi Renaud untuk menanyakan permintaan tersebut kepada istrinya. Walau Claudine tidak memberi jawaban, Renaud tetap berhasil memenuhi hasratnya. Hal ini menggambarkan bahwa posisi Claudine sebagai seorang perempuan dan istri tidak ternilai oleh suaminya saat bertemu dengan perempuan selain dirinya. Hasrat yang tak tertahan kepada perempuan lain telah menyayat perasaan Claudine sebagai seorang istri. Hal inilah yang membuat Claudine haus akan belaian seorang suami. Renaud seakan sibuk dengan pekerjaannya dan juga perempuan lain. Namun, Renaud sangat mengenal sifat Claudine, hingga ia tahu bagaimana cara agar Claudine tetap mengikuti keinginan Renaud.

Sifat penurut yang dimiliki Claudine, membuat Renaud berkuasa atas tubuhnya. Bermula saat pertemuan serta percakapan Claudine dengan para kritikus di Paris, membuat Claudine yang berasal dari kota kecil tergagap dan menjadi rendah diri. Kemudian, Claudine menjadi perempuan pendiam, pemalu dan selalu berada di bayang-bayang suaminya. Renaud yang tahu kelemahan sekaligus kelebihan Claudine justru memanfaatkan situasi ini untuk menguntungkan dirinya sendiri dan menjadikan Claudine sebagai budaknya. Kemampuan Claudine dalam menulis novel dieksploitasi untuk memenuhi popularitas dan peningkatan ekonomi suaminya. Kejanggalan dalam rumah tangga Renaud dan Claudine bermula dari perjodohan yang menimbulkan keterpaksaan dan berakibat ketidakharmonisan dalam rumah tangga. Dalam hal ini, tubuh perempuan berada di bawah kendali laki-laki. Perempuan yang telah menikah tidak lagi memiliki kuasa atas tubuhnya sendiri, sebab tubuhnya secara utuh telah dimiliki oleh suaminya.

Pourquoi est-il venu? pourquoi s'en va-t-il ? Je rêve. Papa est une force de la Nature ; il sert l'obscur Destin. Sans le savoir, il est venu ici, pour que je pusse rencontrer Renaud ; il s'en va, ayant rempli sa mission de père irresponsable...(Colette 1973, 67).

(Kenapa ayah datang? Kenapa ayah pergi? Aku bermimpi. Ayah adalah kekuatan alam ia melayani takdir yang tidak jelas. Tanpa sadar, ayah datang ke sini, supaya aku bisa bertemu Renaud; dia pergi, setelah memenuhi misinya sebagai ayah yang tidak bertanggung jawab.) Pada penjelasan di atas, hak dan kebebasan perempuan dalam menentukan pasangan hidup dikuasai oleh sang ayah. Claudine sebagai sosok penurut dan pendiam, ia tidak dapat berbuat apa pun kecuali menuruti keinginan sang ayah. Tanpa sepengetahuan Claudine, ia dipertemukan dengan Renaud, untuk melangsungkan perjodohan mereka. Tanpa mendapat kesempatan untuk memilih pasangan sendiri, Claudine harus menerima kesepakatan yang telah disetujui ayahnya. Hal ini menyatakan bahwa eksistensi Claudine hanya terlihat saat ia berhasil memenuhi keinginan orang lain. 
Renaud menyadari kemampuan menulis yang dimiliki istrinya hingga ia memperbudak Claudine untuk membuat semua karya novel yang akan dijual dan produksi atas nama Renaud. Claudine selain digunakan sebagai robot seks juga digunakan sebagai penghasil ekonomi oleh suaminya. Claudine tentu saja tidak dapat melakukan pertentangan karena ia sangat takut kepada Renaud dan tidak percaya diri. Hal ini diketahui oleh Renaud, sehingga dengan mudah ia melakukan sesuatu kepada Claudine agar ia mau melakukan walaupun dirinya sedang gunda.

Interseksionalitas representasional mengarah pada citra perempuan hanya menjadi minoritas dan isu perempuan bukan yang signifikan (Crenshaw 1989). Interseksionalitas representasional meliputi cara pembangunan budaya populer membentuk citra perempuan dalam ras dan gender yang berakibat pada marjinalisasi perempuan itu sendiri karena mengabaikan kepentingan utamanya. Ketika martabat perempuan dipandang rendah, pandangan ini akan menjadi perspektif umum. Renaud yang terpukau melihat kata demi kata yang dirangkai Claudine, tetapi dia tidak ingin menunjukkan kepada dunia bahwa Claudine yang menciptakan semua karya yang dipamerkannya. Hal ini menunjukkan pembatasan ruang dalam mengembangkan bakat perempuan. Renaud membatasi ruang istrinya, sehingga dia mendapatkan kepopularitasan dari ruang publik sedangkan Claudine hanya terkenal di ruang domestik.

Ô Claudine! Que j'aime ton âme écolière! Viens que je te respire, cher petit cahier rouvert (Colette 1973, 37).

(O Claudine! Betapa aku mencintai jiwa anak sekolahmu! Kemarilah, aku hirup nafasmu, buku catatan kecil yang dibuka kembali.)

Kalimat di atas menjelaskan tentang laki-laki yang mampu memperdaya perempuan dengan rayuannya. Renaud yang mengetahui kelebihan dan kekurangan istrinya membuatnya mampu membuang amarah sang istri. Claudine yang mulai memberanikan diri untuk meninggalkan masa lalunya menjadi seorang budak dihambat oleh Renaud melalui rayuannya. Rayuan ini dilakukan Renaud agar Claudine kembali membuka buku catatannya terkait melanjutkan cerita novel yang harus dibuatnya. Dalam hal ini, posisi Claudine sebagai seorang istri dimarjinalkan oleh kemampuannya. Claudine sebagai perempuan dan istri di mata Renaud tidak berarti selain kemampuannya dalam menulis. Hal ini berkaitan dengan interseksionalitas representasional di mana posisi perempuan dimarjinalkan di luar martabatnya. Tubuh perempuan sering kali dipakai, dieksploitasi, dan ditindas oleh pemegang kuasa, sehingga lakilaki dapat berkuasa dan memenuhi hasratnya kapan pun yang diinginkannya (Butler 2013). Claudine sebagai perempuan dianggap tidak berarti bagi Renaud selain kemahirannya dalam menulis dan fungsi seksualnya. Anggapan laki-laki tentang ketidakpuasannya jika hanya menikmati hasrat seksual dari satu perempuan saja sehingga laki-laki terus mencari mangsa baru. Tidak ada yang membanggakan bagi kehidupan Claudine dengan menjalankan bahtera rumah tangga seperti itu, meskipun dia adalah istri seorang bangsawan. Claudine hanya dianggap sebagai sesuatu yang dapat memuaskan nafsu laki-laki, terutama Renaud. Hal ini adalah posisi yang sangat rendah bagi perempuan.

J'ai voulu montrer mon beau mari... Est-ce bien un mari que cet amant paternel, ce protecteur voluptueux? (Colette 1973, 47).

(Aku ingin menunjukkan suamiku yang tampan, apakah kekasih dari pihak ayah, pelindung yang menggairahkan ini benar-benar seorang suami?)

Posisi Claudine yang termarjinalkan sebagai seorang anak perempuan membuatnya tak dapat menentukan pilihan sendiri. Kalimat di atas menjelaskan tentang keraguan Claudine terhadap pasangan pilihan sang ayah. Keraguan tersebut muncul atas perlakuan dominasi Renaud terhadap tubuh dan kepiawaian roman Claudine. Dalam kisah ini Claudine dijadikan sebagai dua "robot" sekaligus oleh Renaud, yakni sebagai "robot" seks dan "robot" popularitas dari hasil karya roman Claudine. Claudine tidak ingin harus tunduk pada perintah ayahnya dalam menentukan pilihannya. Dalam kondisi perjodohan yang dilakukan ayahnya membuat Claudine terkekang untuk menjalani kodratnya sebagai perempuan dan seorang istri. 
Perempuan di pandang sebagai sesuatu yang lain (others) dimarjinalkan dengan cara yang tidak pantas, mulai dari segi pekerjaan di mana perempuan dalam hal ini selalu dianggap lemah dan tidak memiliki kekuatan untuk melakukan sesuatu yang besar dan memiliki arti (Irawan 2010). Perjodohan menjadi konsekuensi yang tidak dapat dihindari oleh perempuan. Tidak ada perlawanan dan tidak ada pertentangan. Beauvoir (2003) menyatakan bahwa masyarakat menilai sebuah pernikahan bagi perempuan, hanya sebagai syarat untuk membuktikan keberadaan dirinya dalam komunitasnya. Perempuan menikah hanya karena dua alasan yaitu, untuk meberikan keturunan dan memuaskan kebutuhan seks pasangan suaminya.

Parfois, je cherche à me persuader que peut être l'amour est trop neuf pour moi, tandis que, pour Renaud, il a perdu de son amertume? J'en doute. Nous ne penserons jamais de même ládessus, en dehors de la grande tendresse qui nous a noués (Colette 1973, 14) .

(Terkadang aku mencoba meyakinkan diriku bahwa mungkin cinta terlalu baru untuku, sementara untuk Renaud, dia sudah kehilangan rasa pahitnya? Aku meragukannya. Kita tidak akan pernah memikirkan hal yang sama di atas, terlepas dari kelembutan besar yang telah telah mengikat kita.)

Kalimat di atas menjelaskan tentang posisi tidak berdaya Claudine sebagai perempuan yang tidak memiliki kuasa, tetapi dia tetap menjalankan amanah perjodohan ayahnya. Melalui pernikahan, Claudine yakin bahwa Renaud mampu membawanya ke masa depan yang lebih baik. Perilaku diskriminasi dan ketidakadilan gender yang disimpulkan dari hasil pemikiran dahulu terlihat dari alasan bahwa perempuan memiliki keterbatasan, perempuan bersifat emosional, perempuan dianggap lemah, perempuan hanya diperbolehkan dalam medan domestik. Akibatnya, perempuan terkurung dalam ruang dan wawasan yang sempit. Membatasi perempuan dalam melakukan apa pun yang diinginkan sesuai kebutuhannya dan tidak keluar dari kodratnya, melainkan bagaimana perempuan mampu berpartisipasi untuk membiasakan diri dengan keinginan-keinginannya yang manusiawi dengan dukungan luar melalui aktifasi kemanusiannya. Seorang perempuan yang menciptakan dirinya, atau menjadi apa yang diinginkan, tentu memerlukan keberanian karena sebagian perempuan telah dihantui oleh rasa takut atas pandangan orang luar yang membuatnya menjadi membatasi diri. Seharusnya, perempuan mampu mengakui nila-nilai mereka, tujuan mereka, dan rencana mereka adalah ditentukan oleh kebebasan mereka sendiri.

\section{Perlawanan Perempuan: Perempuan dan Praktik Biseksualitas}

Kekhawatiran Claudine terhadap penindasan laki-laki membuatnya takut untuk menjalin hubungan dengan seorang laki-laki. Hal inilah yang kemudian membuatnya mencari pasangan sesama jenis untuk menghindari terjadinya kekerasan.

Rézi... Toute sa personne fleure un parfum de fougère et d'iris, odeur honnête, simplette et agreste qui surprend et ravit par contraste, car je ne lui découvre rien d'agreste, de simplet, ni, ma foi, d'honnête, elle est bien trop jolie ! Elle m'a parlé de son mari, de ses voyages, de moi, mais je ne sais rien d'elle-même, que son charme (Colette 1973, 79).

(Rézi... Seluruh tubuhnya mengeluarkan aroma pakis dan iris, bau pedesaan terhormat dan terhormat yang aku temukan mengejutkan dan mempesona sebagai kontras, karena aku tidak menemukan sesuatu yang menyenangkan, sederhana, atau, yah, jujur, dia terlalu cantik! Rézi bercerita tentang suaminya, perjalanannya, tentang aku, tetapi aku, tidak tahu apa-apa tentang dirinya kecuali pesonanya.)

Keberadaan sosok Rézi bagi Claudine, mampu menggantikan sosok suaminya sebagai seorang laki-laki. Meskipun Rézi dan Claudine terlahir dengan kesamaan gender, Claudine menganggap bahwa tubuh Rézi adalah sosok laki-laki. Hal ini ditambah dengan perlakuan hangat dari Rézi kepada Claudine, seperti memberikan ruang bicara terhadap setiap jalan pilihan dan karya-karya Claudine. Dari perlakuan spesial ini, Claudine mulai memberanikan diri untuk tampil di depan umum dan menyatakan pendapatnya. 
Selain itu, Rézi memiliki karakter yang seolah seperti Claudine di masa lalunya, saat Claudine mengalami penindasan ganda, baik dari ayah maupun suaminya. Masa itu adalah masa ketika Claudine sebagai seorang perempuan bungkam terhadap penindasan dan mengikuti setiap keinginan orang lain yang tidak ia inginkan. Hal ini kemudian dialami oleh Rézi sehingga Claudine merasa sangat berkuasa pada tubuh Rézi. Claudine merasa mampu mendominasi Rézi. Saat mereka menghabiskan waktu malam bersama, Claudine sangat menikmati dan memanjakan dirinya bersama Rézi. Sebuah perlakuan yang belum pernah dirasakan Claudine dari kekasihnya, di mana ia sangat dihargai dan diberi kesempatan dalam menentukan pilihan.

Selama pernikahan dan kebersamaan bersama suaminya, Claudine hanya melakukan hal-hal untuk memuaskan keinginan orang lain. Dia menuruti semua keinginan suaminya sampai ia tidak mendapatkan hak yang seharusnya pantas untuk didapatkan. Saat Claudine mulai menyadari dan memberanikan diri untuk keluar dari zona penindasan melalui pertemuannya dengan Rézi, ia tidak merasa mengganjal dengan kesamaan gender di antara mereka. Hal ini dilakukan oleh Claudine sebagai satu-satunya cara untuk memuaskan keinginannya dan melawan penindasan yang dialaminya.

Pourquoi vous me plaisez, Claudine? Je pourrais vous dire seulement : « Parce que je vous trouve jolie ", et cela me suffirait, mais ne suffirait pas à votre orgueil... Pourquoi je vous aime? Parce que vos yeux et vos cheveux, du même métal, sont tout ce qui demeure d'une petite statue de bronze clair, devenue chair par le reste ; parce que votre geste rude accompagne bien votre voix douce; parce que votre sauvagerie s'humanise pour moi ; parce que vous rougissez, pour une de vos pensées intimes qu'on devine ou qui s'échappe, comme si une main effrontée s'était glissée sous vos jupes (Colette 1973, 92).

(Kenapa Anda menyukaiku, Claudine? Aku hanya bisa mengatakan kepada Anda: Karena saya menemukan Anda cantik», dan itu akan cukup bagi saya, tetapi tidak akan cukup untuk kebanggaan Anda... Mengapa saya mencintaimu? Karena mata dan rambutmu, dari logam yang sama, adalah semua yang tersisa dari patung perunggu kecil, menjadi daging oleh yang lain; karena gerakan kasarmu berjalan baik dengan suara lembutmu; karena kebiadabanmu adalah manusiawi untukku; karena Anda memerah, untuk salah satu pikiran intim Anda yang orang tebak atau yang lolos, seolah-olah tangan nakal telah menyelinap di bawah rok Anda.)

Sebuah pernyataan dari pasangan perempuan tersebut, menyatakan bahwa mereka saling jatuh cinta dari keindahan fisik yang kemudian memunculkan hasrat untuk memiliki. Kemudian, kesamaan gender yang membuat mereka saling memahami dan menghargai membuat mereka saling mengerti untuk menguatkan pasangannya. Hal ini menjadi satu faktor dan alasan Claudine untuk memilih Rézi sebagai kekasihnya.

Dalam The Laugh of the Medusa (1976), Cixous memperkenalkan istilah biseksualitas dalam bahasa perempuan. Biseksual dalam pemahaman Cixous bukanlah tentang kombinasi seksual seperti androgini, melainkan merupakan perombakan oposisi maskulinitas dan femininitas (Cixous, Cohen, \& Cohen 1976). Biseksualitas tersebut bergerak beyond of gender (Butler 2011). Apabila di dalam bahasa laki-laki stereotip gender sangat terlihat, baik dalam bahasa maupun gaya tulisannya, tidak demikian di dalam biseksualitas. Tidak ada batasan yang berlaku di dalam penulisan biseksualitas. Perempuan menjadi multisubjek, yang berarti ia yang biasa dikonotasikan sebagai objek dengan karakter feminin dapat memosisikan diri sebagai subjek, karena ia memiliki sisi maskulin dalam dirinya.

\section{Perlawanan Perempuan dengan Menjadi Perempuan Independen}

Kesempatan yang terbatas bagi perempuan membuat mereka terus mengembangkan kemampuan intelektualnya agar dapat dihargai dan dipandang tinggi oleh dunia. Hal tersebut menjadi perjuangan bersejarah yang diperjuangkan oleh perempuan sampai saat ini. Perempuan mampu melakukan hal-hal 
yang hanya dianggap layak dilakukan oleh laki-laki. Perempuan memiliki hak untuk mendapatkan posisi setara dengan laki-laki, bukan berarti untuk membandingkan kemampuannya, melainkan mereka menunjukkan bahwa perempuan juga memiliki kemampuan yang sama dan patut diapresiasi. Dalam novel Claudine en Menage perjuangan perempuan digambarkan dalam melawan penindasan yang dilakukan oleh suaminya. Padahal, Claudine memiliki kemampuan dalam menulis sebuah karya, tetapi sang suami tidak menginginkan Claudine diakui sebagai seorang penulis.

Je vis pourtant, je vis dans l'honnêteté la plus nauséeuse. La violence de mon attrait pour Rézi, le sentiment du ridicule, la vanité de ma résistance, tout me presse d'en finir, de m'enivrer d'elle jusqu'à tarir son charme. Et je résiste, ô le triste jeu de syllables ! je m'entête en me méprisant moi-même (Colette 1973, 122).

Namun aku hidup, aku hidup dalam kejujuran yang paling memuakkan. Kerasnya ketertarikanku pada Rézi, perasaan konyol, kesombongan perlawananku, semua mendesakku untuk menyelesaikannya, untuk memabukkan diriku bersamanya sampai aku kehabisan pesonanya. Tapi aku menolak! Dan saya membenci diri sendiri karena keras kepalaku sendiri.

Claudine menjalani kesehariannya penuh hanya untuk memuaskan orang lain. Ia merasa bahwa memiliki pasangan seorang perempuan membuatnya mampu keluar dari paksaan sang suami tetapi ia sadar bahwa perbuatan tersebut akan menyakiti orang-orang yang disayanginya. Pasangan perempuan yang dimilikinya membuat Claudine merasakan kenikmatan dan keberanian baru untuk memulai sebuah hal yang baru. Keinginan besar yang mendorong Claudine untuk melakukan hal tersebut adalah Rézi mampu merasakan apa yang dirasakan oleh Claudine, seperti rasa sakit, penindasan, serta Rézi menjadi tempat untuk meluapkan semua pikirannya dan hasratnya. Namun di sisi lain, Claudine ingin menyelesaikan keinginannya sesaat terlebih ia tau bahwa Claudine dan Rézi tidak akan bisa bersama selamanya.

"Non, non, plus d'amies, plus de femmes!" (Colette 1973, 188)

"Tidak, tidak, tidak ada lagi teman, tidak ada lagi wanita!"

Pilihan untuk memutuskan hubungan khusus dengan Rézi dan suaminya, meyakinkan Claudine bahwa ia mampu menjadi perempuan yang tidak bergantung dengan orang lain. Perpisahan yang menginginkan agar ia tidak kembali jatuh cinta apabila hanya sebagai pelampiasan yang merugikan dirinya. Dari pilihan tersebut, Claudine merasa bahwa ia mampu melawan ikatan-ikatan terhadap dirinya. Ia tidak lagi menulis untuk sang suami, dan keluar dan penindasan yang selama ini membuatnya terkekang. Menjadi perempuan yang mandiri dan terus mengembangkan kemampuannya, membuat Claudine bebas untuk menentukan jalan pilihannya dan tidak tergantung dengan orang lain.

\section{SIMPULAN}

Masalah terkait perempuan, terutama yang sudah menikah, masih sering menjadi pembahasan dalam karya sastra. Hal ini tidak lain disebabkan oleh terbatasnya ruang perempuan dan peran perempuan kerap yang dipandang sebelah mata oleh masyarakat. Status sosial yang rendah cenderung membuat kaum perempuan pasrah dengan perlakuan yang tidak adil, seperti dipekerjakan dalam bentuk paksa, mengalami penindasan dan mendapatkan upah yang rendah.

Keberanian tokoh Claudine bukanlah perlawanan biasa pada abad ke-19, di mana posisi perempuan masih berada dalam dunia patriarki dan ketabuan perempuan melakukan kegiatan di luar ruang domestik (Udasmoro 2015a). Bagi Claudine, memiliki pasangan seorang perempuan semata untuk memuaskan hasratnya yang selama ini tidak terpenuhi. Laki-laki hanya mencari kepuasan seksual saat ia membutuhkan tanpa balik memuaskan pasangannya. Hal inilah yang dialami oleh Claudine, di mana tubuhnya dipakai semena-mena oleh suaminya seolah Claudine adalah seorang robot. Laki-laki 
dan perempuan memiliki hak seksualitas yang sepadan tanpa memandang keadaan biologis yang berbeda antara dua jenis kelamin.

Watak tokoh Claudine sebagai perempuan pendiam dan tidak percaya diri membangkitkan gairah sang suami untuk semakin melakukan penindasan, mengeksploitasi kemampuan Claudine dalam menulis, serta memarjinalkan Claudine saat bertemu dengan perempuan lain. Salah satu cara menentang penindasan yang dilakukan oleh tokoh Claudine diawali melalui hubungannya dengan seorang perempuan bernama Rézi. Keberanian Claudine dalam melawan ketakutan dan ketidakpercayaan dalam dirinya melalui pengakuan kepada suaminya bahwa ia selingkuh dengan kekasih perempuannya. Hal ini menunjukkan bahwa perempuan memiliki hak dalam pemenuhan hasrat seksual dan kesempatan dalam bersuara. Dominasi seksual seorang suami kepada istri dikonstruksi sebagai penguasa seksual sehingga perempuan hanya memuaskan keinginan suami tanpa memenuhi kepuasan diri sendiri. Kemudian, Claudine membuktikan bahwa ia mampu menjadi seorang perempuan independen, berpegang pada kemampuan yang dimilikinya dan tidak bergantung hidup pada orang lain, terutama suami. Keberanian dan kepercayaan diri yang kuat membuatnya mengambil langkah untuk berpisah dengan sang suami dan meninggalkan masa lalunya yang kelam yang penuh keterpaksaan.

\section{DAFTAR PUSTAKA}

Basuki, Teguh \& Arifah Arum Candra Hayuningsih. 2015. “The Life of Gervaise Macquart as A Lower Working Class Women Under French Second Empire in The Novel L'Assomoir by Emile Zola." Humaniora, 27 (1):119-32. DOI:10.22146/jh.6415.

Butler, Judith. 2011. Gender Trouble: Feminism and the Subversion of Identity. New York \& London: Routledge.

2013. Excitable Speech: A Politics of the Performative. New York \& London: Routledge.

Cixous, Hélène, Keith Cohen, \& Paula Cohen. 1976. "The Laugh of the Medusa.” Signs, 1 (4): 875-93.

Colette, Sinodie-Gabrielle. 1973. Claudine en Ménage. Paris: Gallimard.

Collins, Patricia Hill. 2000. Black Feminist Thought: Knowledge, Consciousness, and the Politics of Empowerment. United Kingdom: Psychology Press.

Crenshaw, Kimberlé. 1989. "Demarginalizing the Intersection of Race and Sex: A Black Feminist Critique of Antidiscrimination Doctrine, Feminist Theory and Antiracist Politics." The University of Chicago Legal Forum, 1: 31.

Humaeni, Ayatullah. 2016. "Tabu Perempuan dalam Budaya Masyarakat Banten.” Humaniora 27 (2): 174-85. DOI: $10.22146 /$ jh. 10585.

Irawan, Windy Warna. 2010. "Negara dan Hak Asasi Kelompok Minoritas Seksual Lesbian, Gay, Biseksual, Transgender/Transeksual, Interseks, dan Queer.” Skripsi. Depok: Universitas Indonesia.

Lee Bartky, Sandra. 1998. "Foucault, Femininity, and the Modernization of Patriarchal Power." Dalam The Politics of Women's Bodies (Sexuality, Appearance, and Behavior), disunting oleh Rose Weitz. New York \& London: Oxford University Press. 
Lon, Yohanes Servatius \& Fransiska Widyawati. 2018. "Bride-Wealth: Is There Respect for Women in Manggarai, Eastern Indonesia?" Humaniora 30 (3): 271-78. DOI: 10.22146/jh.29216.

MacClintock, A. 1993. "Family Feuds: Gender, Nationalism and the Family" Feminist Review, 44:61-80.

Mohanty, Chandra Talpade. 2003. Feminism without Borders: Decolonizing Theory, Practicing Solidarity. Duke: Duke University Press.

Mottier, Véronique. 2013. Sexuality: A Very Short Introduction. Oxford: Oxford University Press.

Nasiru, La Ode Gusman. 2017. “Transformasi Perempuan dari 'Liyan' Ke 'Diri' dalam Tiga Cerita Rakyat Kulisusu: Analisis Wacana Feminisme.” Poetika : Jurnal Ilmu Sastra, 5 (1): 2635. DOI:10.22146/poetika.v5i1.25996.

Sentana, Yuli Mahmudah. 2016. "The Lure of Image: Kebohongan pada Narasi Perempuan dalam Syngue Sabour Pierre de Patience Karya Atiq Rahimi." Poetika: Jurnal Ilmu Sastra, 4 (2):119-28. DOI:10.22146/poetika.v4i2.15493.

Udasmoro, Wening. 2012. "Konsep Nasionalisme dan Hak Reproduksi Perempuan: Analisis Gender terhadap Program Keluarga Berencana di Indonesia.” Humaniora, 16 (2):147-54.

— 2015a. "Gypsies in 19th-Century French Literature: The Paradox in Centering the Periphery." Jurnal Kata, 17 (1). DOI:10.9744kata.17.126-32.

- 2015b. "Paradoksalitas Pemosisian Perempuan dalam Novel Colomba Karya Prosper Mérimée." Kawistara, 5 (1):1-11.

Yuval-Davis, Nira. 2011. "Power, Intersectionality and the Politics of Belonging." Dalam . FREIA's tekstserie, No. 75. Denmark: Institut for Kultur og GlobaleStudier, Aalborg Universitet. https://doi.org/10.5278/freia.58024502.

Zabihzadeh, Seyedeh Robabeh, Ruzy Suliza Hashim, dan GCCC Wei. 2015. "Domestic violence against women in Atiq Rahimi's The Patience Stone." Gema online Journal of Language Studies 15 (1): 51-66. 